\title{
KEMAMPUAN MENGANALISIS STRUKTUR TEKS CERAMAH MENGGUNAKAN MEDIA YOUTUBE PADA PESERTA DIDIK KELAS XI IPS 1
}

\section{ABILITY TO ANALYZE TEXTILE TEXT STRUCTURE USING YOUTUBE MEDIA IN STUDENTSCLASS XI IPS 1}

\author{
Desi Aprianty; Rustam Effendi; Sainul Hermawan \\ Program Studi Pendidikan Bahasa dan Sastra Indonesia \\ FKIP Universitas Lambung Mangkurat \\ desiaprianty1@gmail.com
}

\begin{abstract}
Abstrak
Penelitian ini bertujuan untuk mengukur kemampuan menganalisis struktur teks ceramah menggunakan media youtube pada peserta didik kelas XI IPS 1. Metode yang digunakan pada penelitian ini adalah metode deskriptif dan jenis penelitian yang digunakan adalah kuantitatif. Penelitian ini berupa hasil kerja peserta didik menjawab soal stuktur teks dengan pokok bahasan teks ceramah. Penelitian ini diambil di kelas XI IPS 1 SMAN 4 Banjarmasin. Teknik pengumpulan data melalui observasi dan tes. Kemudian langsung dianalisis dengan teknik analisis deskriptif kuantitatif. Hasil kemampuan menganalisis struktur teks ceramah peserta didik menunjukkan bahwa nilai mean yang didapat adalah 82,1 berada dalam kategori tinggi. Pada aspek pokok bahasan setiap paragraf, nilai mean yang didapat adalah 78,1 berada dalam kategori cukup. Pada aspek menyusun struktur teks ceramah, nilai mean yang didapat adalah 78,0 berada dalam kategori cukup.

Kata kunci:kemampuan menganalisis, teks ceramah, media youtube
\end{abstract}

\begin{abstract}
This study aims to measure the ability to analyze the structure of text lectures using Youtube media on students of class XI IPS 1. The method used in this study is descriptive method and the type of research used is quantitative. This research is in the form of work results of students answering text structure questions with the subject of the lecture text. This study was taken in the XI IPS 1 class at SMAN 4 Banjarmasin. Techniques for collecting data through observation and tests. Then directly analyzed by quantitative descriptive analysis techniques. The results of the ability to analyze the structure of the lecture text of students showed that the mean value obtained was 82.1 in the high category. In the main aspects of each paragraph, the mean value obtained is 78.1 in the sufficient category. In the aspect of structuring the lecture text, the mean value obtained is 78.0 in the sufficient category.
\end{abstract}

Keywords: analytical skills, text lectures, youtube media 


\section{Pendahuluan}

Perkembangan teknologi dan informatika saat ini sudah sangat maju dalam berbagai bidang. Semua perkembangan yang terjadi juga mempengaruhi penggunaan media dalam proses pembelajaran. Sebelum adanya perkembangan teknologi, pemakaian media dalam pembelajaran terbatas adanya. Penggunaan media dalam pembelajaran yang beragam diharapkan akan meningkatkan rasa antusias peserta didik dalam kegiatan pembelajaran.

Dengan demikian pemakaian media dalam proses pembelajaran di kelas, satu diatara banyak cara agar meningkatkan semangat peserta didik untuk belajar. Mengingat selama ini proses pembelajaran yang dilakukan hanya berfokus kepada materi pembelajaran dan penyampaian yang monoton. Satu dari sekian banyak upaya dalam mengurangi rasa bosan peserta didik pada saat belajar yaitu menciptakan situasi belajar mengajar yang memungkinkan peserta didik mengeluarkan semua kemampuannya. Dalam hal ini, media pembelajaran dapat menjadi penunjang yang efektif dalam proses pembelajaran yang tidak membosakan dan membuat peserta didik mengembangkan kemampuannya.

Pada kegiatan pembelajaran, fungsi media pembelajaran untuk wadah dan penyalur pesan dari guru agar sampai ke peserta didik. Dari penjelasan sebelumnya, maka semakin jelas bahwa media pengajaran menempati bagian dari kebutuhan akan saranan penunjang pembelajaran. Serta tidak dapat dipungkiri dalam rangka menyukseskan program belajar peserta didik yang ingin dicapai. Namun tidak sesuai dengan rencana yang dibuat, nyatanya pengguna media pembelajaran dilapangan masih kurang banyak yang memahami bahkan menggunakan media pendidikan dengan benar. Banyak guru yang masih menggunakan teknik ceramah sebagai satu-satunya sumber belajar selain papan tulis. Kecenderungan menggunakan teknik ceramah dalam proses pembelajaran meningkatkan rasa bosan peserta didik pada pembelajaran.

Media pembelajaran bukan hanya alat untuk guru bermalas-malasan dalam proses pembelajaran, tetapi diharapkan membantu guru dalam menerangkan meteri yang dibahas kepada murid dan dapat membangun suasana belajar mengajar yang menyenangkan.

Berkaitan pula dengan jam pembelajaran, peserta didik diharuskan sudah sampai di sekolah pada jam 07.00 WITA sedangkan kebanyakan acara ceramah/dakwah yang di tayangkan televisi mulai jam 07.30 WITA. Hal tersebutlah yang membuat kurangnya waktu untuk mendengarkan ceramah pada 
peserta didik dan pegawai kantoran yang di haruskan sudah berada di tempat kerja. Hal ini juga yang sangat membantu dalam pembelajaran peserta didik. Seperti yang terdapat dalam kurikulum 2013, pada kompetensi dasar pertama tiga titik enam yaitu "Menganalisis isi, struktur, dan kebahasaan dalam teks ceramah" model pembelajaran lama yang menggunakan contoh teks ceramah terlampir sudah dapat digantikan dengan adanya media-media terbaru. Dengan harapan mampu menumbuhkan kreatifitas peserta didik maupun pengajar.

Sama seperti teks pada umumnya, teks ceramah juga memiliki struktur yang tidak dapat di abaikan. Dalam suatu wacana, baik wacana tulis maupun lisan memiliki struktur yang berbeda-beda. Struktur tersebut meliputi struktur makro dan mikro. Setiap kali penyampaian dakwah, seorang ustaz memiliki topik atau inti pembicaraan yang jelas. Topik-topik yang di pilih bisa mengenai semua aspek yang dapat diterima masyarakat banyak. Topik tersebut dapat dibagi menjadi beberapa subtopik untuk mempermudah penyampaian materi ceramah.

Perkembangan teknologi tersebutlah yang bisa menunjang kualitas proses pembelajaran mengajar. Bermacam media yang dipakai dalam aktifitas pembelajaran akan membuat suasana saat pembelajaran lebih nyaman, menarik dan menyenangkan. Satu diantara banyak media pembelajaran yang berkembang dan sering di gunakan saat ini adalah audiovisual. Media pembelajaran memiliki peranan dalam kegiatan belajar mengajar, yaitu sebagai alat bantu dari pengajar menyampaikan materi ke peserta didik. Sebelum adanya perkembangan yang terjadi dalam hal media pembelajaran, pada awal mula media sekedar dianggap alat bantu mengajar pendidik. Itulah mengapa penggunaan media belajar di beberapa sekolah kurang beragam, mulai dari faktor alat elektronik yang tidak memadai atau kemampuan pendidik yang belum mengerti cara menggunakan alat tersebut.

Umumnya perkembangan teknologi yang sedang terjadi, hendaknya dapat mempermudah semua kegiatan manusia. Tidak terkecuali dengan perubahan media pembelajaran yang dilakukan pendidik dalam melakukan kegiatan belajar mengajar. Sebagai seorang peserta didik di era modern ini, diharapkan juga bisa menerima media-media baru yang digunakan pengajar dalam mendukung kegiatan belajar mengajar. Ada baiknya pengajar maupun peserta didik tidak terpaku dengan media yang telah biasa di pakai.

Hal itu jugalah yang menarik bagi peneliti ingin melakukan penelitian tersebut, untuk mengetahui bagaimana 
kemampuan peserta didik dalam pembelajaran ketika media pembelajaran yang biasanya menggunakan cetakan diganti dengan media yang mengikuti perkembangan zaman. Berdasarkan beberapa alasan di atas, penulis akan melakukan penelitian "Kemampuan Menganalisis Struktur Teks Ceramah Menggunakan Media Youtube Pada Peserta Didik Kelas XI IPS 1 SMAN 4 Banjarmasin".

\section{Metode Penelitian}

Pada penelitian ini peneliti menggunakan Metode deskriptif. Sedangkan jenis penelitian yang digunakan adalah kuantitatif. Data berupa hasil kerja peserta didik menjawab soal stuktur teks dengan pokok bahasan teks ceramah. Tempat pengambilan data pada kelas XI IPS 1 di SMAN 4 Banjaramsin. Teknik pengumpulan data yang digunakan adalah observasi, dan tes.

\section{Hasil Penelitian dan Pembahasan}

\section{Kemampuan Menganalisis Struktur}

\section{Teks Ceramah Menggunakan Media}

\section{Youtube Peserta Didik}

Memahami struktur teks ceramah adalah hal yang harus dikuasai oleh peserta didik, sebab dalam pembelajaran teks ceramah tanpa mengetahui struktur yang dimiliki tidak mungkin peserta didik dapat memahami lebih dalam tentang teks ceramah. Dalam penelitian ini ada 10 butir pertanyaan yang berkaitan dengan menganalisis struktur teks ceramah. 10 butir pertanyaan yang dimaksud adalah butir soal nomor 1, 2, 3, 4, 5, 6, 7, 8, 9 dan 10. Kemampuan peserta didik dalam menganalisis struktur teks ceramah dapat dilihat melalui hasil jawaban peserta didik dalam menjawab soal tes analisis struktur teks ceramah yang diserahkan oleh guru. Jumlah peserta didik kelas XI IPS 1 yang berhasil menjawab dengan tepat pada setiap butir soal pertanyaan mengenai struktur teks ceramah dapat dilihat pada gambar. 
Tabel 4

Jumlah Peserta Didik Kelas XI IPS 1 SMA Negeri 4 Banjarmasin yang

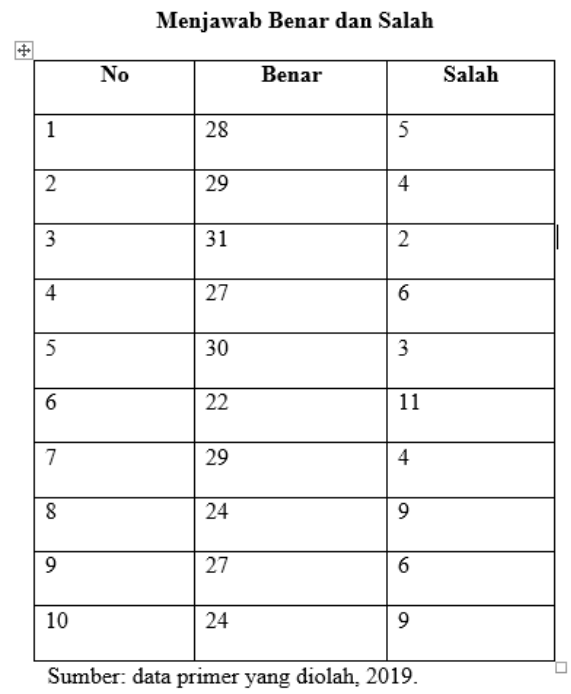

Gambar 1. Jawaban benar dan salah

Sesuai data pada gambar di atas, dapat diketahui bahwa mean peserta didik banyak menjawab benar secara keseluruhan pada soal no 3 yakni 31 peserta didik, sedangkan rata-rata peserta didik banyak menjawab salah pada soal nomor 6 yaitu 11 peserta didik.

Pada tingkat analisis struktur teks ceramah ini, diketahui bahwa nilai mean peserta didik kelas XI IPS 1 SMAN 4 Banjarmasin yaitu 82,1 dengan nilai terendah 50 sedangkan nilai tertinggi 100 .

\begin{tabular}{|c|c|c|c|}
\hline \\
\hline \multicolumn{4}{|c|}{$\begin{array}{c}\text { Tabel } 5 \\
\text { Distribusi Frekuensi Tunggal Kemampuan Menganalisis Struktur } \\
\text { Teks Ceramah Menggunakan Media Youtube Peserta Didik Kelas XI IPS }\end{array}$} \\
\hline \multicolumn{4}{|c|}{ I SMA Negeri 4 Banjarmasin } \\
\hline No & Skor & Frekuensi & Presentase (\%) \\
\hline 1 & 50 & 1 & 3,0 \\
\hline 2 & 60 & 3 & 9,0 \\
\hline 3 & 70 & 7 & 21,2 \\
\hline 4 & 80 & 6 & \begin{tabular}{|l|}
18,1 \\
\end{tabular} \\
\hline 5 & \begin{tabular}{|l|}
90 \\
\end{tabular} & 9 & \begin{tabular}{|l|}
27,2 \\
\end{tabular} \\
\hline 6 & \begin{tabular}{|l|}
100 \\
\end{tabular} & 7 & 21,2 \\
\hline
\end{tabular}

Gambar 2. Menganalisis Stuktur

Sesuai gambar di atas, dapat diketahui bahwa nilai terendah adalah 50 yang didapat oleh satu peserta didik dengan presentase 3,0\%. Sedangkan nilai tertinggi adalah 100, didapat oleh 7 peserta didik dengan presentase 21,2\%. Dari skor peserta didik pada gambar 2 di atas, lalu dikategorikan pada gambar 3.

\begin{tabular}{|c|c|c|c|}
\hline \multicolumn{4}{|c|}{ Banjarmasin } \\
\hline No & Batas Skor & Kategori & Frekuensi \\
\hline 1 & $0-59,9$ & Sangat Rendah & 1 \\
\hline 2 & $60-69,9$ & Rendah & 3 \\
\hline 3 & $70-79,9$ & Cukup & 7 \\
\hline 4 & $80-89,9$ & Tinggi & 6 \\
\hline 5 & \begin{tabular}{|l|}
$90-100$ \\
\end{tabular} & Sangat Tinggi & 16 \\
\hline
\end{tabular}

Gambar 3. Kriteria penskoran

Sesuai gambar 3 yang menunjukkan ada 1 peserta didik memiliki kemampuan 
menganalisis struktur teks ceramah menggunakan media youtube yang sangat rendah. Dari 33 peserta didik, 3 peserta didik memiliki kemampuan menganalisis struktur teks ceramah menggunakan media youtube yang rendah. 7 peserta didik memiliki kemampuan struktur teks ceramah menggunakan media youtube yang cukup. 6 peserta didik memiliki kemampuan struktur teks ceramah menggunakan media youtube yang tinggi, dan 16 peserta didik memiliki kemampuan struktur teks ceramah menggunakan media youtube yang sangat tinggi.

\section{Kemampuan Menganalisis Pokok Bahasan setiap Paragraf}

Menganalisis pokok bahasan sebuah bacaan juga tak kalah penting dari menganalisis struktur bacaan. Sebab dengan memahami pokok bahasan atau ide pokok sebuah bacaan, kita dapat mengetahui apa yang dibahas dalam bacaan tersebut. Pokok bahasan bisa juga disebut dengan gagasan utama, yaitu ide yang menjadi pokok atau pikiran utama dalam mengembangkan paragraf suatu bacaan.

Pada penelitian ini ada 10 butir pertanyaan yang berkaitan dengan menganalisis pokok bahasan setiap paragraf teks ceramah. Adapun 10 butir pertanyaan yang dimaksud yaitu pertanyaan nomor $11,12,13,14,15,16$, 27, 18, 19, dan 20. Kemampuan peserta didik dalam menganalisis pokok bahasan teks ceramah dapat diukur melalui jawaban hasil mengerjakan soal yang diberikan mengenai menganalisis struktur teks ceramah yang diberikan oleh guru, yang berkaitan dengan ide pokok. Penjabaran dari hasil jawaban peserta didik dapat di lihat pada gambar 4 .

Tabel 7

Jumlah Peserta Didik Kelas XI IPS 1 SMA Negeri 4 Banjarmasin yang

Menjawab Benar dan Salah

\begin{tabular}{|l|l|l|l|l|l|}
\hline No. Soal & Salah & Benar & No Soal & Salah & Benar \\
\hline $\mathbf{1 1}$ & 7 & 26 & $\mathbf{1 6}$ & 6 & 27 \\
\hline $\mathbf{1 2}$ & 8 & 25 & $\mathbf{1 7}$ & $\mathbf{8}$ & 25 \\
\hline $\mathbf{1 3}$ & 10 & 23 & $\mathbf{1 8}$ & 8 & 25 \\
\hline $\mathbf{1 4}$ & 5 & 28 & $\mathbf{1 9}$ & 7 & 26 \\
\hline $\mathbf{1 5}$ & 6 & 27 & $\mathbf{2 0}$ & 6 & 27 \\
\hline
\end{tabular}

Gambar 4. Jumlah jawaban peserta didik 
Berdasarkan data pada tabel 4 mean peserta didik berhasil menjawab benar secara keseluruhan adalah no 14, yaitu sebanyak 28 peserta didik. Sedangkan ratarata peserta didik banyak menjawab salah adalah pada soal nomor 13, yaitu sebanyak 10 peserta didik.

Pada tingkat pemahaman pokok bahasan ini, mean skor peserta didik adalah 78,1 dengan nilai terendah 40 dan nilai tertinggi 100 .

Tabel 8

Distribusi Frekuensi Tunggal Kemampuan Menganalisis pokok bahasan setiap paragraf Peserta Didik Kelas XI IPS I SMA Negeri 4 Banjarmasin

\begin{tabular}{|l|l|l|l|}
\hline No & Skor & Frekuensi & Presentase (\%) \\
\hline 1 & 40 & 1 & 3,0 \\
\hline 2 & 50 & 2 & 6,0 \\
\hline 3 & 60 & 3 & 9,0 \\
\hline 4 & 70 & 8 & 24,2 \\
\hline 5 & 80 & 7 & 21,2 \\
\hline 6 & 90 & 6 & 18,1 \\
\hline 7 & 100 & 6 & 18,1 \\
\hline
\end{tabular}

Gambar 5. Distribusi frekuensi

Dari gambar 5, dapat dilihat bahwa nilai terendah adalah 40 yang didapat oleh satu peserta didik dengan presentase $3,0 \%$. Nilai tertinggi adalah 100, didapat oleh 6 peserta didik dengan presentase $18,1 \%$. Dari skor peserta didik sesuai gambar 5, selanjutnya dikategorikan lagi pada gambar 6.

Tabel 9

Kriteria Penskoran Kemampuan Menganalisis pokok bahasan setiap
paragraf Peserta Didik Kelas XI IPS I SMA Negeri 4 Banjarmasin
\begin{tabular}{|l|l|l|l|}
\hline No & Batas Skor & Kategori & Frekuensi \\
\hline 1 & $0-59,9$ & Sangat Rendah & 3 \\
\hline 2 & $60-69,9$ & Rendah & 3 \\
\hline 3 & $70-79,9$ & Cukup & 8 \\
\hline 4 & $80-89,9$ & Tinggi & 7 \\
\hline 5 & $90-100$ & Sangat Tinggi & 12 \\
\hline
\end{tabular}

Gambar 6. Kriteri Penskoran menganalisis pokok bahasan

Sesuai gambar 6, memperlihatkan bahwa ada 3 peserta didik yang memiliki kemampuan menganalisis pokok bahasan setiap paragraf yang sangat rendah. Dari 33 peserta didik, 3 peserta didik berada pada tingkatan kemampuan memahami pokok bahasan pada kategori rendah. 8 peserta didik mempunyai kemampuan memahami pokok bahasan dalam kategori cukup. 7 peserta didik mempunyai kemampuan memahami pokok bahasan pada kategori tinggi, dan 12 peserta didik mempunyai kemampuan memahami pokok bahasan pada kategori sangat tinggi. 
Kemampuan Menyusun Struktur Teks Ceramah Peserta Didik

Selain menganalisis struktur teks ceramah dan juga pokok bahasan, hal yang tak kalah penting juga adalah menyusun struktur teks ceramah. Struktur teks ceramah yang sesuai dengan ketentuannya membuat teks ceramah yang dibaca atau didengar lebih mudah dipahami dan dimengerti isinya.

Dalam penelitian ini ada 4 butir pertanyaan yang berkaitan dengan menyusun struktur teks ceramah. Adapun 4 butir pertanyaan yang dimaksud yaitu pertanyaan nomor 21, 22, 23, dan 24 . Kemampuan peserta didik dalam menyusun struktur teks ceramah dapat diukur melalui hasil jawaban pada soal teks ceramah yang diberikan oleh guru tentang struktur teks ceramah. Jumlah peserta didik kelas XI IPS 1 yang berhasil menjawab benar dan salah pada setiap butir soal mengenai struktur teks ceramah dapat dilihat pada gambar.
Tabel 10

Jumlah Peserta Didik Kelas XI IPS I SMA Negeri 4 Banjarmasin yang Menjawab Benar dan Salah

\begin{tabular}{|l|l|l|}
\hline No. Soal & Salah & Benar \\
\hline 21 & 9 & 24 \\
\hline 22 & 5 & 28 \\
\hline 23 & 8 & 25 \\
\hline 24 & 7 & 26 \\
\hline \multicolumn{2}{|l|}{ Sumber: data primer yang diolah, 2019} \\
\hline
\end{tabular}

Gambar 7. Jumlah menjawab benar dan salah

Sesuai data pada gambar 7 dapat diketahui bahwa mean peserta didik banyak menjawab benar pada soal no 22 , yakni 28 peserta didik. Sedangkan rata-rata peserta didik banyak menjawab salah pada soal nomor 21, yakni 9 peserta didik.

Pada tingkat menyusun struktur teks ceramah ini, diketahui bahwa nilai mean peserta didik kelas XI IPS 1 SMAN 4 Banjarmasin adalah 78,0 dengan nilai terendah 25 dan nilai tertinggi 100 .

Tabel 11

Distribusi Frekuensi Tunggal Kemampuan Menyusun struktur teks ceramah Peserta Didik Kelas XI IPS 1 SMA Negeri 4 Banjarmasin

\begin{tabular}{|l|l|l|l|}
\hline No & Skor & Frekuensi & Presentase (\%) \\
\hline 1 & 25 & 3 & 9,0 \\
\hline 2 & 50 & 5 & 15,1 \\
\hline 3 & 75 & 10 & 30,3 \\
\hline 4 & 100 & 15 & 45,4 \\
\hline
\end{tabular}

Gambar 8. Distribusi Frekuensi 
Dari gambar 8, dapat diketahui bahwa nilai terendah yaitu 25 yang didapat 3 peserta didik dengan presentase $9,0 \%$. Nilai tertinggi adalah 100, didapat 15 peserta didik dengan presentase $45,4 \%$.

Dari skor peserta didik sesuai gambar 8 , lalu akan di kategorikan sesuai gambar 9.

Tabel 12

Kriteria Penskoran Kemampuan Menyusun Struktur Teks Peserta Didik Kelas XI IPS I SMA Negeri 4 Banjarmasin

\begin{tabular}{|l|l|l|l|}
\hline No & Batas Skor & Kategori & Frekuensi \\
\hline 1 & $0-59,9$ & Sangat Rendah & 8 \\
\hline 2 & $60-69,9$ & Rendah & - \\
\hline 3 & $70-79,9$ & Cukup & 10 \\
\hline 4 & $80-89,9$ & Tinggi & - \\
\hline 5 & $90-100$ & Sangat Tinggi & 15 \\
\hline
\end{tabular}

Gambar 9. Kriteri Penskoran menganalisis pokok bahasan

Sesuai gambar 9, menunjukkan bahwa ada 8 peserta didik yang memiliki kemampuan menyusun struktur teks ceramah dalam kategori sangat rendah. Dari 33 peserta didik, 10 peserta didik memiliki kemampuan menyusun struktur teks ceramah dalam kategori cukup dan 15 peserta didik memiliki kemampuan menyusun struktur teks ceramah dalam kategori sangat tinggi.

\section{Simpulan dan Saran}

\section{Simpulan}

Sesuai hasil penelitian dapat diambil kesimpulan bahwa kemampuan menganalisis struktur teks ceramah menggunakan media youtube peserta didik kelas XI IPS 1 SMA Negeri 4 Banjarmasin sudah cukup baik. Karena SMAN 4 Banjarmasin memiliki nilai KKM Bahasa Indonesia sebesar 75 . Peserta didik yang mendapatkan nilai di atas KKM dalam aspek menganalisis struktur teks ceramah sebanyak 29 orang, dengan rata-rata kemampuan menganalisis struktur teks ceramah sebanyak 82,1 termasuk dalam kategori tinggi. Dalam aspek kedua, yaitu menganalisis pokok bahasan teks ceramah peserta didik yang mendapatkan nilai di atas KKM sebanyak 27 orang dengan rata-rata nilai 78,1 termasuk dalam kategori sedang. Kemudian pada aspek ketiga, yaitu menyusun struktur teks ceramah siswa yang mendapatkan nilai di atas KKM 27 orang dengan ratarata nilai 78,0 termasuk dalam kategori sedang.

Sesuai data pada pembahasan dapat diketahui bahwa nilai rata-rata tertinggi terdapat dalam aspek pertama yaitu menganalisis struktur teks ceramah dengan perolehan rata-rata-nilai 82,1. Sedangkan nilai mean terendah ada pada 
aspek menyusun struktur teks ceramah dengan perolehan nilai 78,00 dalam kategori sedang.

\section{Saran}

Bagi guru, diharapkan pembelajaran lebih berpedoman pada Rencana Pelaksanaan Pembelajaran (RPP) agar pengelolaan waktu lebih tepat dan kompetensi pembelajaran yang diinginkan tercapai. Pemakaian media yang beragam juga dapat meningkatkan pemahaman peserta didik dalam proses pembelajaran. Penggunaan media yang monoton akan mengakibatkan peserta didik bosan dengan proses belajar yang mengakibatkan kurangnya pemahaman peserta didik.

Penilaian yang dilakukan menggunakan rubrik penilaian. Kemampuan menganalisis struktur teks peserta didik lebih diperhatikan dan guru lebih banyak memberikan latihan pembelajaran menggunakan mediamedia elektronik yang masih jarang digunakan sebelumnya agar pembelajaran di kelas lebih nyaman.

Bagi siswa, diharapkan untuk lebih sering berlatih dan mengembangkan kemampuan menganalisis struktur teks agar lebih menguasai pembelajaran.

\section{Daftar Pustaka}

Anggraini, Diah Retno. (2018). Pemanfaatan Youtube Sebagai Media Pembelajaran dalam Meningkatkan Kreatifitas Guru Bahasa Inggris Mts Al-Insan. Tanggerang: Universitas Muhammadiyah Tanggerang. (Publikasi Daring).

Asyhar,Rayanda. (2012). Kreatif Mengembangkan Media Pembelajaran. Jakarta: Gaung Persada (GP) Press Jakarta.

AW, Suranto. (2005). Komunikasi Perkantoran: Edisi 1. Yogyakarta: Media Wancana.

Azhar, Arsyad. 1996. Media Pembelajaran. Jakarta: PT Raja Grafindo Persada.

Chaer, Abdul. (2007). Linguistik Umum. Jakarta: Rineka Cipta.

Chaidir, Moh Arfian. (2017). Video SMA:

Bahasa

Indonesia-Ceramah.

(Online),(http://sumberbelajar.seamolec .org/product.php?id=NTk5MjYzYjY4N jVlYWMxYjI1ZjQ3OTMz), diakses 13 Februari 2019.

Darma, Yoce Aliah. (2014). Analisis Wacana Kritis. Bandung: Yrama Widya.

Eriyanto. 2001. Analisis Wacana: Pengantar Analisis Teks Media. Yogyakarta: LkiS Yogyakarta. 
Ghozali, Imam. (2009). Aplikasi Analisis

Multivariate dengan Program SPSS.

Semarang: UNDIP.

Iwantara, I. W. dkk. (2014). Pengaruh

Penggunan Media Video Youtube dalam Pembelajaran IPA Terhadap Motivasi Belajar dan Pemahaman Konsep Siswa. Singaraja: Universitas Pendidikan Ganesha. (Publikasi Daring).

Kridalaksana, Harimurti. (2008). Kamus Linguistik. Jakarta: Gramedia Pustaka Utama.

Lestari, Renda. (2017). Penggunaan Youtube Sebagai Media Pembelajaran Bahasa Inggris. Muara Bungo: STKIP Muhammadiyah Muara Bungo. (Publikasi Daring).

Mahsun. (2011). Metode Penelitian Bahasa: Tahapan Strategi, Metode, dan Tekniknya. Jakarta: PT Raja Grafindo Persada.

Moleong, Lexy J. (2009). Metode Penelitian Kualitatif. Bandung: Remaja Rosdakarya.

Mulyana. (2005). Kajian Wacana: Teori, Metode, dan Aplikasi Prinsip-prinsip Analisis Wacana. Yogyakarta: Tiara Wacana.

Prastati, Trini, dan Prasetya Irawan. (2005). Media Sederhana. Jakarta: PAU Dirjen Dikti Depdiknas.

Qudsyiah, Mizan. (2019). Ceramah Singkat: Tips Meninggalkan Maksiat.
(Online), (https://yufid.tv/37019ceramah-singkat-tips-meninggalkanmaksiat-ustadz-mizan-qudsyiah-lc-ma.html), diakses 13 Februari 2019.

Rusman. (2012). Pembelajaran Berbasis Teknologi Informasi dan Komunikasi: Mengembangkan Profesionalitas Guru. Jakarta: Raja Wali Pers.

Sadiman, S Arief. (2003). Media Pendidikan: Pengertian, Pengembangan, dan Pemanfaatannya. Jakarta: PT Raja Grafindo Persada.

Sanjaya, Wina. (2010). Strategi Pembelajaran Berorientasi Standar Proses Pendidikan. Jakarta: Prenada Media Group.

Sugiyono. (2016). Metode Penelitian Kuantitatif, Kualitatif dan $R \& D$. Bandung: PT Alfabeta.

Suherli, Maman, dkk. (2017). Bahasa Indonesia. Jakarta: Kementerian Pendidikan dan Kebudayaan.

Sumarlam. (2003). Teori dan Praktek Analisis Wacana. Surakarta: Pustaka Cakra.

Suwarno, Muji. (2017). Potensi Youtube Sebagai Sumber Belajar Matematika. Malang: Universitas Negeri Malang. (Publikasi Daring).

Taniredja, T. dan Hidayati Mustafidah. (2012). Penelitian Kuantitatif (Sebuah Pengantar). Bandung: Penerbit Alfabeta. 
Trianto. (2010). Mendesain Model Pembelajaran InovatifProgresif. Jakarta: Kencana.

Wigati, Sofyani. dkk. (2018). Pengembangan Youtube. Pembelajaran Berbasis Ki Hadjar Dewantara untuk Materi Integral di SMA. Yogyakarta: Universitas Sarjanawiyata Tamansiswa. (Publikasi Daring).

Winkel. (2009). Psikologi Pengajaran. Yogyakarta: Media Abadi. 